\title{
Measurement of the temperature of density maximum of water solutions using a convective flow technique
}

\author{
M.F. Cawley *, D. McGlynn, P.A. Mooney \\ Department of Experimental Physics, National University of Ireland, Maynooth, County Kildare, Ireland
}

Received 4 August 2005

Available online 7 February 2006

\begin{abstract}
A technique is described which yields an accurate measurement of the temperature of density maximum of fluids which exhibit such anomalous behaviour. The method relies on the detection of changes in convective flow in a rectangular cavity containing the test fluid. The normal single-cell convection which occurs in the presence of a horizontal temperature gradient changes to a double cell configuration in the vicinity of the density maximum, and this transition manifests itself in changes in the horizontal temperature profile across the cavity. The method is applied to a variety of water solutions.
\end{abstract}

(C) 2006 Elsevier Ltd. All rights reserved.

Keywords: Free convection; Water; Density anomaly; Density maximum; Aqueous solutions

\section{Introduction}

The majority of substances expand when heated. A notable exception is water: when water at $0{ }^{\circ} \mathrm{C}$ and at a pressure of one atmosphere is heated, its density increases to a maximum value of $999.972 \mathrm{~kg} \mathrm{~m}^{-3}$ at $3.98^{\circ} \mathrm{C}$. Thereafter, the density decreases with further heating in the usual manner. The magnitude of this anomalous behaviour is small compared with the anomaly of water's expansion upon freezing - the latter corresponds to an $8.3 \%$ change in volume, compared with a $0.013 \%$ volume contraction between $0{ }^{\circ} \mathrm{C}$ and $4{ }^{\circ} \mathrm{C}$ (Fig. 1). Neither of these anomalies in the behaviour of water is as yet well understood. Various molecular models (e.g. [1-4]) rely primarily on the nature of the hydrogen bond in water to account for these (and other) anomalous properties. Solid-liquid phase change anomalies are found in some other substances, notably Gallium and Bismuth [5], both of which expand by about $3 \%$ on going from the molten to the solid state, a property

\footnotetext{
${ }^{*}$ Corresponding author. Fax: +35317083313.

E-mail address: michael.cawley@nuim.ie (M.F. Cawley).
}

which is exploited in fine-detail casting. Hydrogen bonding plays no role in such elemental metals. It is not clear if any of these substances exhibit a density maximum in the liquid state under normal pressure conditions. A density maximum has been reported for Gallium [6], but under conditions of negative pressure (i.e. tension). Water and its solutions are the only clearly documented examples of liquids which exhibit a density maximum.

The temperatures of maximum density of a variety of water solutions have been summarized in the International Critical Tables [7]; these data were obtained by a number of researchers using standard density measurement techniques. The early work of Despretz $[8,9]$ led to the law named after that investigator: "the lowering of the temperature of the point of maximum density of water caused by the addition of a solute is directly proportional to the concentration of the latter" [10]. Later work by Rosetti [11,12] attempted to link this rule with the behaviour of the depression of the freezing point of water solutions. The latter, however, is a colligative property of solutions, viz. it depends on the number of solute particles in solution, but not on the nature of the solute, whereas the shift of the temperature of density maximum was found to depend 


\begin{tabular}{|llll|}
\hline Nomenclature & & \\
& & & \\
$c_{0}$ & water state function coefficient $\left(\mathrm{kg} \mathrm{m}^{-3}\right)$ & $T_{\mathrm{c}}$ & temperature of the cold side chamber $\left({ }^{\circ} \mathrm{C}\right)$ \\
$c_{1}$ & water state function coefficient $\left(\mathrm{kg} \mathrm{m}^{-3}{ }^{\circ} \mathrm{C}^{-1}\right)$ & $T_{\mathrm{h}}$ & temperature of the warm side chamber $\left({ }^{\circ} \mathrm{C}\right)$ \\
$c_{2}$ & water state function coefficient $\left(\mathrm{kg} \mathrm{m}^{-3}{ }^{\circ} \mathrm{C}^{-2}\right)$ & $T_{\rho \max }$ & temperature of density maximum $\left({ }^{\circ} \mathrm{C}\right)$ \\
$\mathbf{g}$ & gravitational acceleration vector $\left(\mathrm{m} \mathrm{s}^{-2}\right)$ & $(u, v)$ & velocity components $\left(\mathrm{m} \mathrm{s}^{-1}, \mathrm{~m} \mathrm{~s}^{-1}\right)$ \\
$h$ & height of test chamber $(\mathrm{m})$ & $\mathbf{v}$ & velocity vector $\left(\mathrm{m} \mathrm{s}^{-1}\right)$ \\
$p$ & pressure $(\mathrm{Pa})$ & $w$ & width of test chamber $(\mathrm{m})$ \\
$t$ & time $(\mathrm{s})$ & $\alpha$ & coefficient of thermal diffusivity $\left(\mathrm{m}^{2} \mathrm{~s}^{-1}\right)$ \\
$T$ & temperature $\left({ }^{\circ} \mathrm{C}\right)$ & $\mu$ & dynamic viscosity $\left(\mathrm{kg} \mathrm{m}^{-1} \mathrm{~s}^{-1}\right)$ \\
$T_{\mathrm{i}, \mathrm{c}}$ & initial temperature of cold side chamber $\left({ }^{\circ} \mathrm{C}\right)$ & $\rho$ & density of liquid $\left(\mathrm{kg} \mathrm{m}^{-3}\right)$ \\
$T_{\mathrm{i}, \mathrm{h}}$ & initial temperature of warm side chamber $\left({ }^{\circ} \mathrm{C}\right)$ & & \\
& & & \\
\hline
\end{tabular}

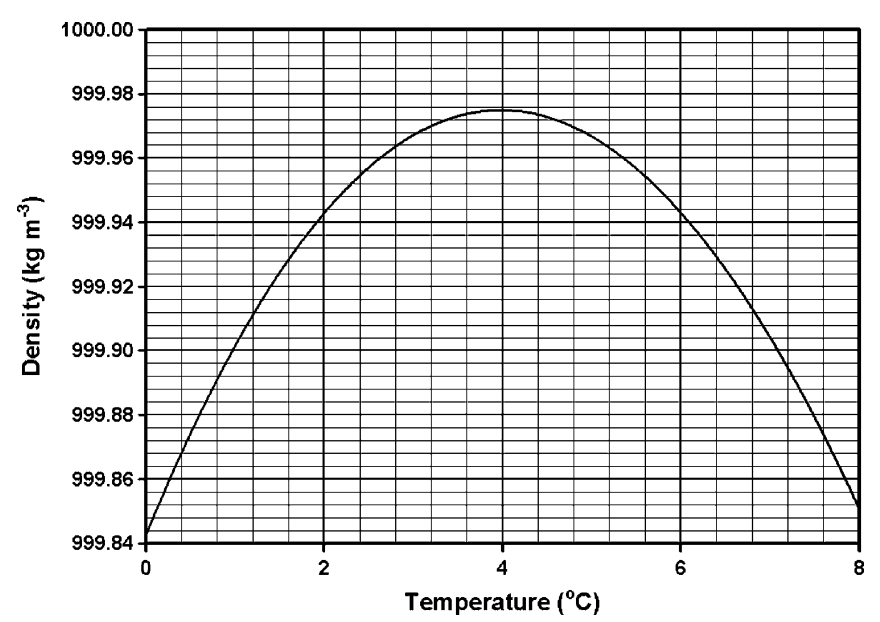

Fig. 1. Density profile of pure water at $101 \mathrm{kPa}$ in the vicinity of the density maximum.

both on the nature and the concentration of the dissolved substance.

While the anomalous behaviour of the density of water close to the freezing point was suspected at least since the early work of the 17th century Galilean Accademia del Cimento in Florence, it was some time before this effect was disentangled from complications induced by volume changes in the containing vessel. The existence of the density maximum in pure water was established beyond doubt through a series of experiments by Hope, which relied on detecting a temperature inversion within the liquid, arising from natural convection, rather than bulk changes in the volume of the water [13]. Few direct methods of determining the temperature of the density maximum have been reported. The majority of measurements of the temperature of density maximum for various aqueous solutions used dilatometers (devices similar to mercury thermometers) in which the test liquid revealed its expansion or contraction via changes in length of a liquid column in a thin-bore glass tube. Compensating techniques were used to allow for changes in the volume of the dilatometer bulb (e.g. [10]).
A novel approach to direct detection and measurement of the temperature of the density maximum was reported by Caldwell [14]. The method relies on detecting a reversal in the temperature change when the water sample is subjected to a sudden (adiabatic) reduction in pressure. It is potentially an accurate approach as it involves detection of a zero crossing rather than an extremum in the density curve. However, it is difficult to implement, and to our knowledge it has only been used to measure the temperatures of density maximum of the saline solutions reported in the original paper. In this paper a technique is described which permits direct detection of the density maximum and yields an accurate measurement of the change in the temperature of the density maximum as a function of solute concentration (at a pressure of one atmosphere). The method relies on the detection of an anomalous feature in a series of temperature sensor profiles as the liquid sample is slowly cooled through the region of maximum density. Computational fluid dynamics (CFD) is used to explain the origins of the anomalous feature, and results are presented of maximum density temperature measurements for a variety of aqueous solutions (ionic salts, sugars, ketones, and alcohols) over a range of solute concentrations.

\section{Experimental apparatus and procedure}

The experiment is a modified version of the system described in a previous publication [15]. The liquid test sample is placed in a metal enclosure of dimensions $0.12 \mathrm{~m}$ (length) by $0.06 \mathrm{~m}$ (depth) by $0.06 \mathrm{~m}$ (height) which is clamped between two larger containers on either side. Coolant is continually pumped through these side chambers in order to maintain a controlled temperature gradient across the test sample. The three containers are placed in the refrigerator compartment of a standard refrigerator/ freezer unit, which also provides the coolant for the circulating fluid in the colder $\left(T_{\mathrm{c}}\right)$ side chamber. A second refrigerator/freezer unit is used to provide the coolant for the warmer $\left(T_{\mathrm{h}}\right)$ side chamber. The temperatures of the coolant reservoirs (70\% water, 30\% ethylene glycol) are maintained by simple heat exchangers operating between copper coils 


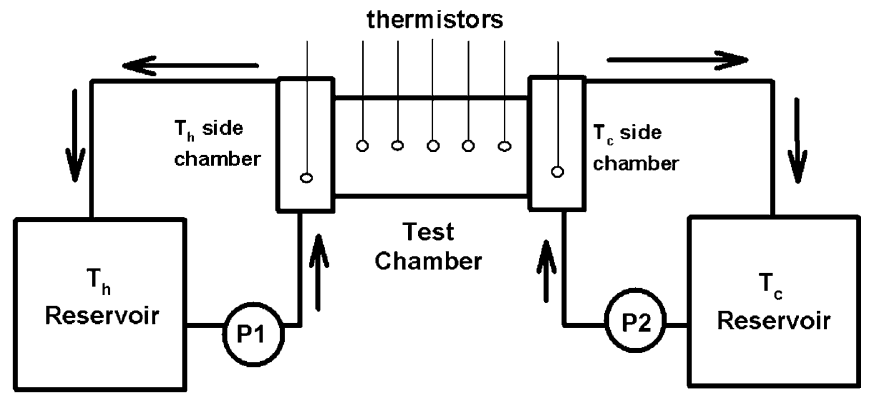

Fig. 2. Overview of the apparatus. P1 and P2 are pumps under computer control.

in the freezer compartments and similar coils within the reservoirs. The apparatus is illustrated schematically in Fig. 2. Five thermistors are arranged in a horizontal line along the centre of the test chamber, at distances of $0.02 \mathrm{~m}, 0.04 \mathrm{~m}, 0.06 \mathrm{~m}, 0.08 \mathrm{~m}$ and $0.1 \mathrm{~m}$ relative to the left $\left(T_{\mathrm{h}}\right)$ wall. Thermistors are also placed in the two side chambers, the two coolant reservoirs, and in the refrigerator compartment containing the experiment in order to monitor the ambient temperature. All thermistors are calibrated against a standard thermometer to an accuracy of $0.1^{\circ} \mathrm{C}$.

A typical experimental sequence is as follows. The test sample is initially held between side boundary temperatures of $10{ }^{\circ} \mathrm{C}\left(T_{\mathrm{h}}\right)$ and $6{ }^{\circ} \mathrm{C}\left(T_{\mathrm{c}}\right)$ until the five thermistors reach a mean temperature of $8{ }^{\circ} \mathrm{C}$. The side chamber temperatures are now decremented simultaneously (under computer control) by $0.1^{\circ} \mathrm{C}$ at 9 -min intervals until $T_{\mathrm{h}}$ reaches $2{ }^{\circ} \mathrm{C}$ and $T_{\mathrm{c}}$ reaches $-2{ }^{\circ} \mathrm{C}$, giving a total of 81 steps with an overall duration of $43,740 \mathrm{~s}(12.15 \mathrm{~h})$. Thus the temperature gradient remains constant throughout the experiment $\left(\mathrm{a} 4{ }^{\circ} \mathrm{C}\right.$ temperature difference across $0.12 \mathrm{~m}$ ) but the mean temperature of the water sample is cooled from $8{ }^{\circ} \mathrm{C}$ to $0{ }^{\circ} \mathrm{C}$. The purpose of this slow cooling is to bring the water sample through the region of the density maximum in a quasisteady-state manner. The temperature is recorded continuously in the side chambers and at the five points along the central horizontal axis through the test chamber.

\section{Results for pure ethanol and pure water}

The results of the procedure described in Section 2 when applied to a fluid with no density anomaly (in this case, pure ethanol) are shown in Fig. 3. It is evident that the thermistor curves associated with the five temperature probes in the test sample follow the mean temperature from $8{ }^{\circ} \mathrm{C}$ down to $0^{\circ} \mathrm{C}$. The structure which is apparent in the thermistor profiles for the $T_{\mathrm{h}}$ and $T_{\mathrm{c}}$ side chambers is due to the discontinuous $0.1{ }^{\circ} \mathrm{C}$ temperature steps which occur every $9 \mathrm{~min}$. The steady temperature gradient maintains a single clockwise convective cell which flows close to the boundaries of the test enclosure, similar to what is observed in pure water at temperatures well above the anomaly region (see Fig. 6b). Since the fluid in the central region of the chamber remains comparatively undisturbed,

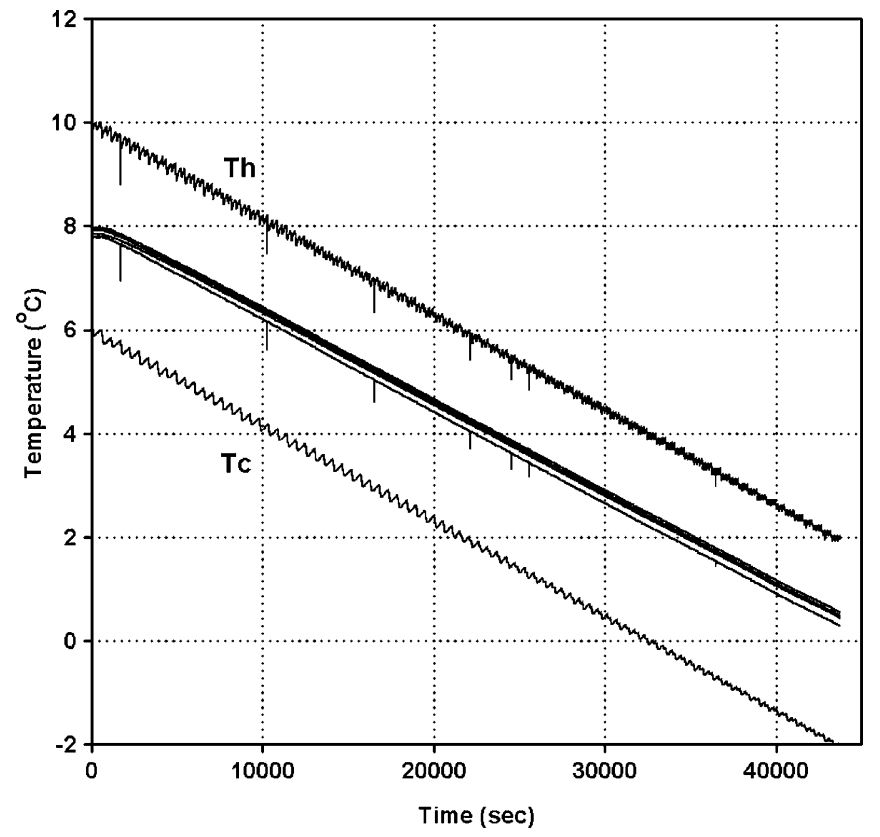

Fig. 3. Temperature against time for pure ethanol in the test chamber. The uneven structure on the $T_{\mathrm{h}}$ and $T_{\mathrm{c}}$ side-chamber profiles arises from the $-0.1^{\circ} \mathrm{C}$ steps which occur at 9 -min intervals. The profiles associated with the five thermistors within the test chamber are closely bunched together, and follow the uniform cooling trend from $8{ }^{\circ} \mathrm{C}$ to $0^{\circ} \mathrm{C}$.

the temperature gradient across the thermistor array is small and all thermistors remain within $0.2{ }^{\circ} \mathrm{C}$ of each other throughout the entire experiment.

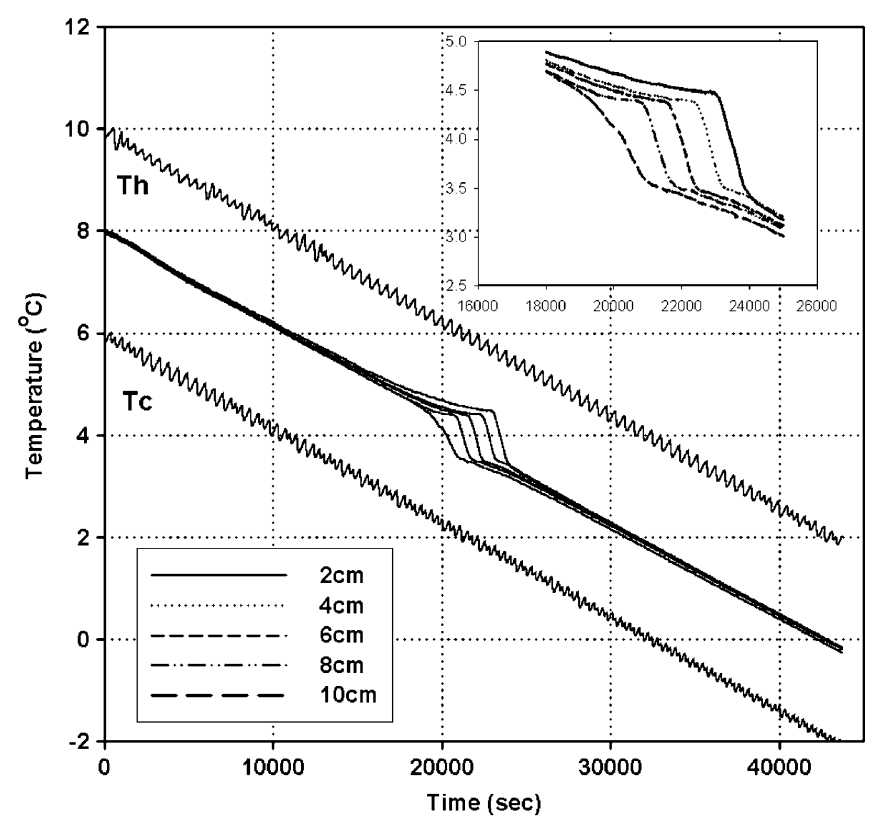

Fig. 4. Temperature against time for pure water in the test chamber. The inset shows the behaviour of the thermistor profiles in the vicinity of the density anomaly in greater detail. The thermistor closest to the $T_{\mathrm{c}}$ side chamber (at position $10 \mathrm{~cm}$ ) is the first to show rapid cooling due to the formation of the counter-clockwise convective cell, followed by the other thermistors in sequence from right to left. 
The thermistor profiles for a pure water experiment are shown in Fig. 4. The feature centred on $4{ }^{\circ} \mathrm{C}$ and $2.5 \times 10^{4} \mathrm{~s}$ arises due to the water density anomaly. The dispersal of the five thermistor curves in this region is caused by the formation and gradual development of a counter-clockwise convective cell which commences in the lower right of the test chamber (as the $T_{\mathrm{c}}$ wall is the first to sense the anomaly at $4{ }^{\circ} \mathrm{C}$ ). The formation of a double convective cell structure in a rectangular enclosure in the vicinity of the density anomaly is well documented (e.g. [16-19]).

\section{Measurement of the shift of the temperature of density maximum - CFD validation and uncertainty estimation}

The experimental observations were complemented with simulations from the computational fluid dynamics program NaSt [20] further details of modifications to this CFD routine are given in [15]. The program predicts the temperature, velocity and pressure of a Newtonian, incompressible fluid by solving the Navier-Stokes, continuity and Fourier equations

$$
\begin{aligned}
& \rho \frac{\partial \mathbf{v}}{\partial t}+\rho(\mathbf{v} \cdot \nabla) \mathbf{v}=-\nabla p+\rho(T) \mathbf{g}+\mu \nabla^{2} \mathbf{v} \\
& \nabla \cdot \mathbf{v}=0 \\
& \frac{\partial T}{\partial t}+\mathbf{v} \cdot \nabla T=\alpha \nabla^{2} T
\end{aligned}
$$

The viscosity and the thermal diffusivity are assumed constant and are assigned their appropriate values for pure water at $4{ }^{\circ} \mathrm{C}$ as follows [5]:

$$
\begin{aligned}
& \mu=1.567 \times 10^{-3} \mathrm{~kg} \mathrm{~m}^{-1} \mathrm{~s}^{-1} \\
& \alpha=1.344 \times 10^{-7} \mathrm{~m}^{2} \mathrm{~s}^{-1} \\
& \text { and gravity, } g=9.81 \mathrm{~m} \mathrm{~s}^{-2}
\end{aligned}
$$

The Boussinesq approximation is assumed, whereby the temperature dependence of the density is only considered in the buoyancy term of the Navier-Stokes equation. This temperature dependence is described by the following state function based on a second-order polynomial fit to data taken from [5]:

$\rho(T)=c_{0}+c_{1} T+c_{2} T^{2}$

where $c_{0}=999.845079 \mathrm{~kg} \mathrm{~m}^{-3}, c_{1}=0.06378 \mathrm{~kg} \mathrm{~m}^{-3}{ }^{\circ} \mathrm{C}^{-1}$ and $c_{2}=-0.0080125 \mathrm{~kg} \mathrm{~m}^{-3}{ }^{\circ} \mathrm{C}^{-2}$ (with $\rho(T)$ in $\mathrm{kg} \mathrm{m}^{-3}$ ). The temperature of density maximum is then given by

$T_{\rho \max }=-c_{1} /\left(2 c_{2}\right)=3.980^{\circ} \mathrm{C}$

The two-dimensional geometry is assumed to represent a vertical 2-D slice of the three-dimensional test chamber used for the experimental observations. The boundary conditions imposed on this geometry are (see also Fig. 5).

No slip for all boundaries

$u=v=0$

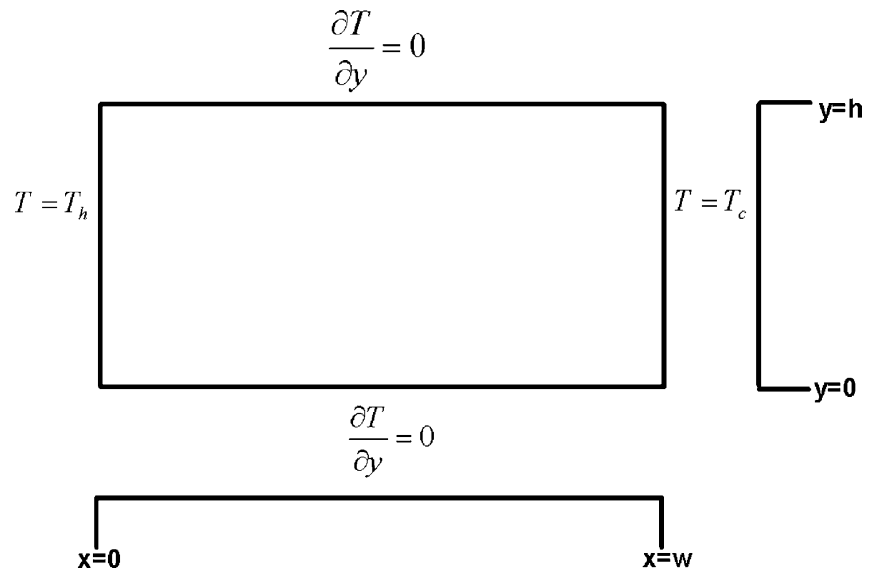

Fig. 5. Boundary conditions used in the CFD model.

Horizontal boundaries are adiabatic

$\frac{\partial T}{\partial y}=0$ on planes $y=0$ and $y=h$

Vertical boundaries are isothermal

$T=T_{\mathrm{h}}$ and $T=T_{\mathrm{c}}$ for $x=0$ and $x=w$, respectively.

The dimensions of the geometry are $h=0.06 \mathrm{~m}$ and $w=0.12 \mathrm{~m}$. The vertical boundaries were assigned initial temperature values of $T_{\mathrm{i}, \mathrm{h}}=10^{\circ} \mathrm{C}$ and $T_{\mathrm{i}, \mathrm{c}}=6^{\circ} \mathrm{C}$, and these values were decremented by $0.1^{\circ} \mathrm{C}$ after time intervals of $540 \mathrm{~s}$ until the final temperatures of $T_{\mathrm{h}}=2{ }^{\circ} \mathrm{C}$ and $T_{\mathrm{c}}=-2^{\circ} \mathrm{C}$ were reached, giving a total simulated time of $43740 \mathrm{~s}(12.15 \mathrm{~h})$.

The results from this model are presented in Fig. 6(a)(g). The overall trends of the temperature profile are in good agreement with the experimental results. The temperature profiles show the expected plateaux followed by the sharp descent in temperature. This feature is centred on $4{ }^{\circ} \mathrm{C}$ in both the experimental and numerical results. The convective flow pattern generated by the numerical model reveals the single clockwise convective cell at the start of the cooling sequence, the growth of the counter-clockwise cell from the cold boundary across the chamber until it completely dominates the convective flow. The grid independence of the numerical solution was analysed using uniform grids in the range $10 \times 5$ (width by height) to $60 \times 30$. The behaviour of a global parameter (in this case, the integral of the temperature over the entire grid) was examined for convergence, and it was found that the value of the average temperature was relatively independent of grid size for grids in excess of $30 \times 15$ (less than $0.3 \%$ variation in the average temperature above this mesh size, compared with a $5 \%$ variation in this parameter in going from a $10 \times 5$ to $30 \times 15$ grid). A range of time steps was also tested, and it was found that the solution was relatively independent of step size for time steps in the range $0.01-1.0 \mathrm{~s}$; a time step of $0.1 \mathrm{~s}$ was used in the simulations.

Simulated temperature profiles for two different temperatures of maximum density $\left(4.0^{\circ} \mathrm{C}\right.$ and $\left.3.0^{\circ} \mathrm{C}\right)$ are shown in 


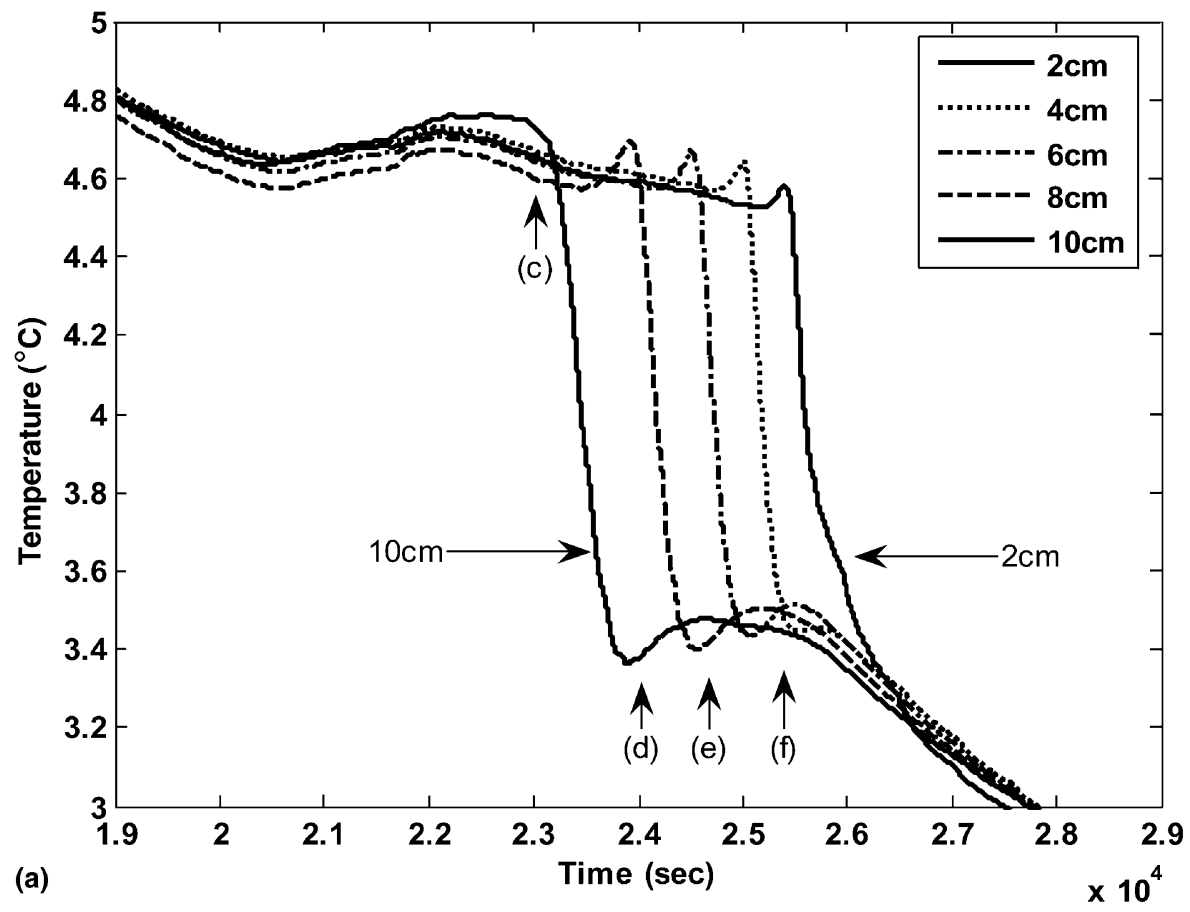

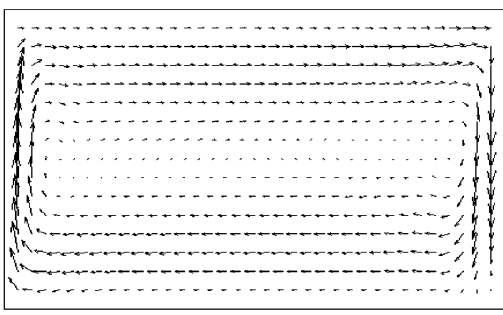

(b)

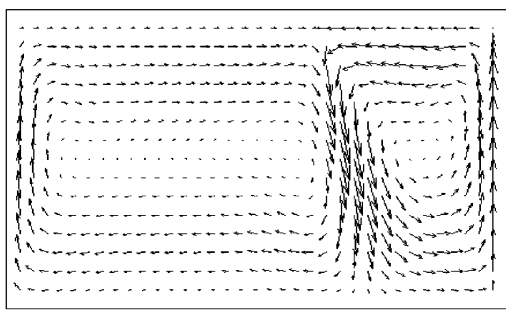

(d)

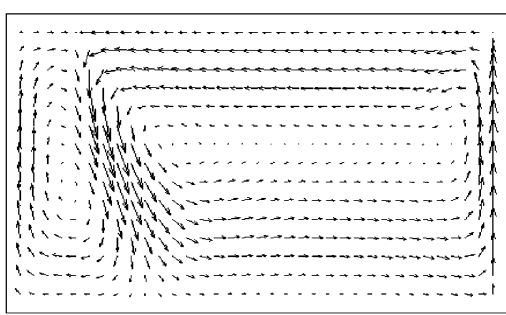

(f)

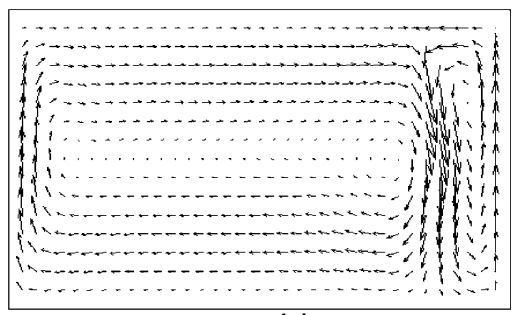

(c)

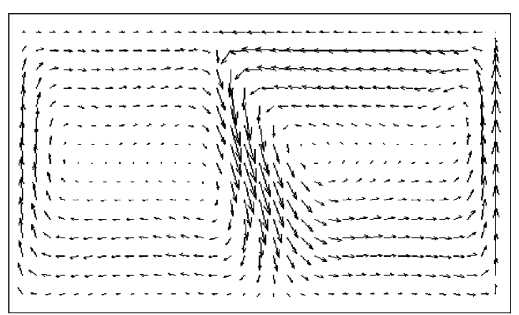

(e)

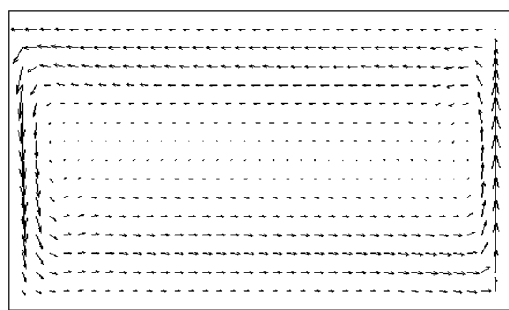

(g)

Fig. 6. (a) Simulated anomaly region for pure water. (b)-(g): velocity quiver plots for a sequence of times during the simulation: (b) and (g) correspond to the flow predicted near the start and end of the simulation, respectively; (c), (d), (e), and (f) correspond to the times indicated by arrows in (a).

Fig. 7, along with the results of a chi-squared comparison between these two profiles (the appropriate values for the quadratic coefficient $c_{2}$ are -0.0079725 and -0.01063 , respectively). The chi-squared comparison between such profiles permits the extraction of the shift in the temperature of maximum density. A chi-squared sum is formed 

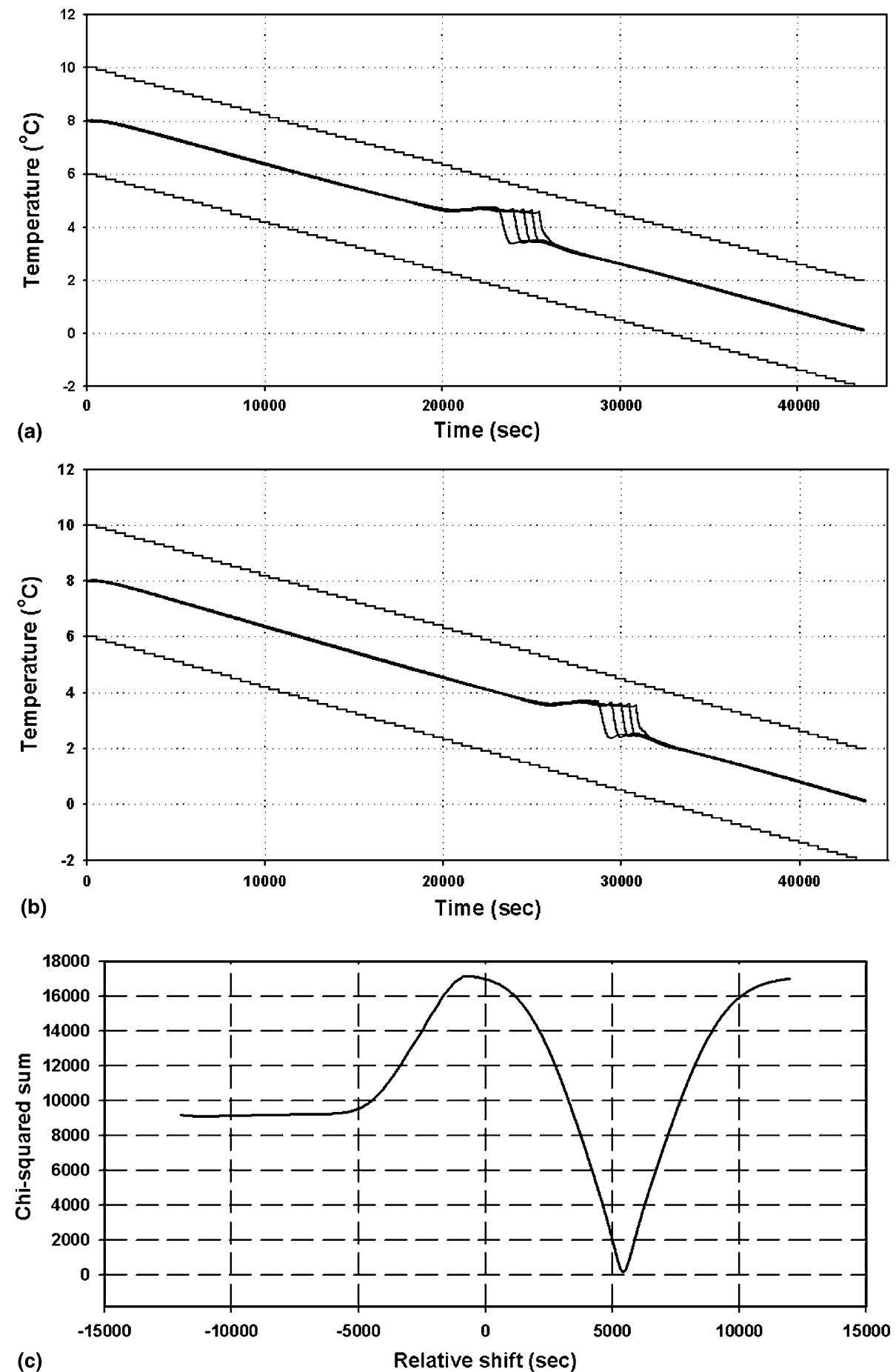

Fig. 7. (a) Simulated temperature profiles for a fluid with a density maximum at $4.00{ }^{\circ} \mathrm{C}$. (b) Simulated temperature profiles for a fluid with a density maximum at $3.00^{\circ} \mathrm{C}$. (c) Chi-squared comparison between (a) and (b).

by accumulating the squared differences for each of the five temperature probes within the test region. This sum is recalculated as the test profile is shifted relative to the control profile in the direction of the slope of the $T_{\mathrm{h}}$ and $T_{\mathrm{c}}$ cooling curves, i.e. the test anomaly feature is superimposed upon the control feature and the two sets of temperature profiles are shifted relative to each other until an optimal overlap is achieved, as signified by a minimum in the chi-squared sum
(Fig. 7c). The corresponding shift in the temperature of maximum density is then calculated from

$T_{\rho \max }=($ slope $) \cdot($ position of chi-squared minimum $)+4{ }^{\circ} \mathrm{C}$

where the slope of the $T_{\mathrm{h}}$ or $T_{\mathrm{c}}$ profile is given by

slope $=\left(2{ }^{\circ} \mathrm{C}-10^{\circ} \mathrm{C}\right) /(43740)=-1.829 \times 10^{-4}{ }^{\circ} \mathrm{C} \mathrm{s}^{-1}$ 
For the simulated example given in Fig. 7, the minimum in the chi-squared plot occurs at a relative time shift of $5421 \mathrm{~s}$, giving a temperature of maximum density of

$T_{\rho \max }=\left(-1.829 \times 10^{-4}\right) \cdot(5421)+4=3.01{ }^{\circ} \mathrm{C}$

It is evident that the uncertainty associated with the chisquared procedure is negligible when it is applied to simulated data. A larger uncertainty (typically of order $\pm 0.1^{\circ} \mathrm{C}$ ) is found when the method is applied to repeated experimental runs of the same solute and concentration. This gives rise to an overall error in the determination of $T_{\rho \max }$ of $\pm 0.14{ }^{\circ} \mathrm{C}$ when combined in quadrature with the $0.1^{\circ} \mathrm{C}$ uncertainty associated with the absolute calibration of the thermistors. To allow for uncertainties in solution preparation, particularly at low concentrations, a conservative error of $\pm 0.2{ }^{\circ} \mathrm{C}$ is assumed to apply to all measurements of $T_{\rho \max }$ reported in this work.

\section{Temperatures of maximum density for aqueous solutions}

The technique described in the previous sections was applied to a variety of aqueous solutions. The temperature profile for a typical solution $(7 \mathrm{~g} / \mathrm{l}$ of $\mathrm{NaCl})$ is shown in Fig. 8. It is evident that the anomaly feature is depressed below $4{ }^{\circ} \mathrm{C}$. The chi-squared comparison between Fig. 8 and the control run of pure water (Fig. 4) is given in Fig. 9. Using the procedure described in Section 4, the resulting temperature of maximum density is found to be $2.53 \pm 0.2{ }^{\circ} \mathrm{C}$ for this particular aqueous solution. Results for a range of aqueous solutions are summarized in Figs. 10 and 11. Fig. 10 shows the temperature of maximum density as a function of solute concentration expressed in grams per litre; Fig. 11 presents the same results in terms

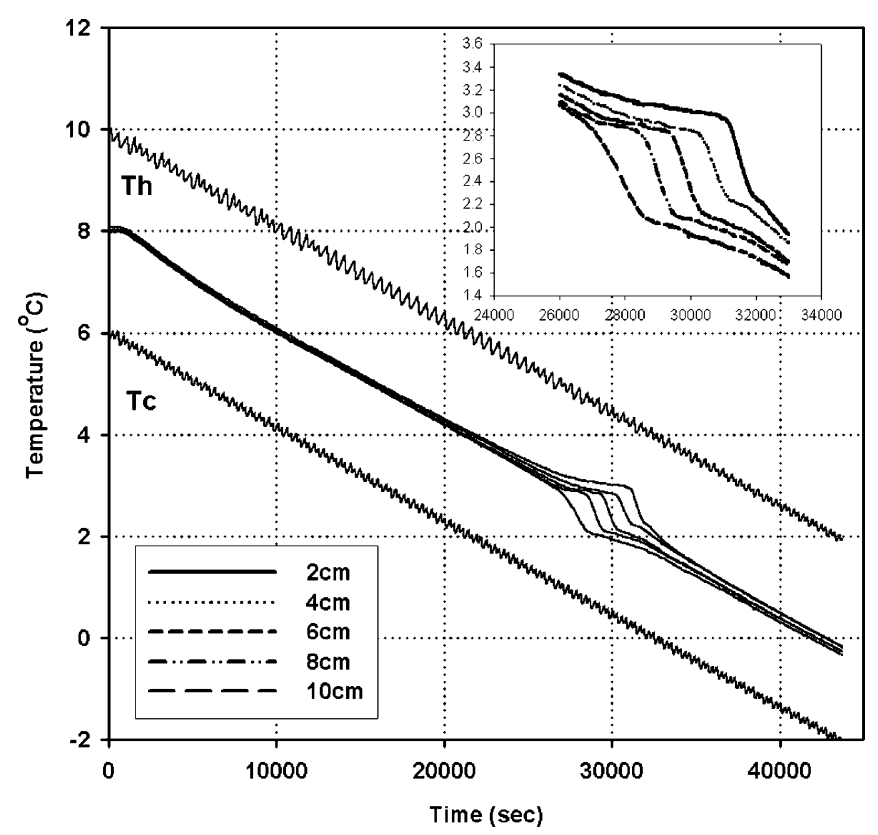

Fig. 8. Temperature against time for $7 \mathrm{~g} / 1 \mathrm{NaCl}$ aqueous solution. The temperature of maximum density is depressed to $2.53{ }^{\circ} \mathrm{C}$.

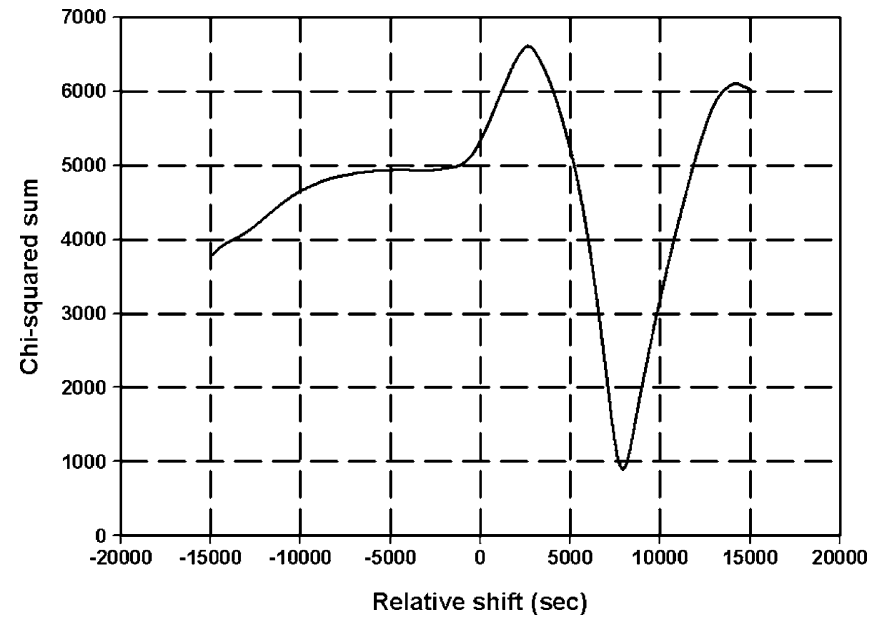

Fig. 9. Chi-squared comparison between the thermistor profiles for pure water (Fig. 4) and a $7 \mathrm{~g} / 1 \mathrm{NaCl}$ solution (Fig. 8).
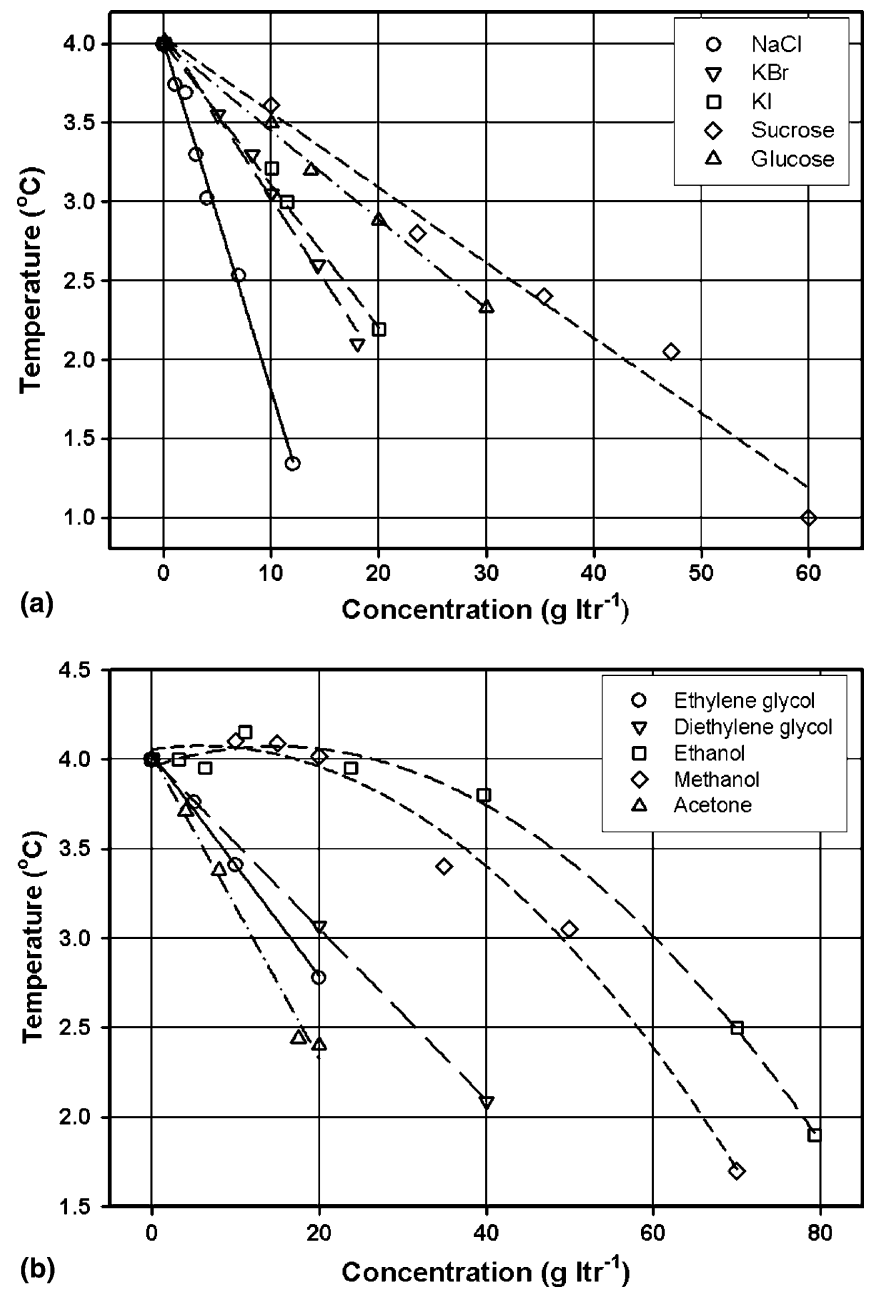

Fig. 10. Behaviour of the temperature of maximum density as a function of mass concentration (expressed in grams per litre) for a range of solutes. (a) Linear depressions observed for ionic salts and sugars and (b) nonlinear trends observed for methanol and ethanol, and linear depressions observed for ethylene glycol, diethylene glycol, and acetone. 

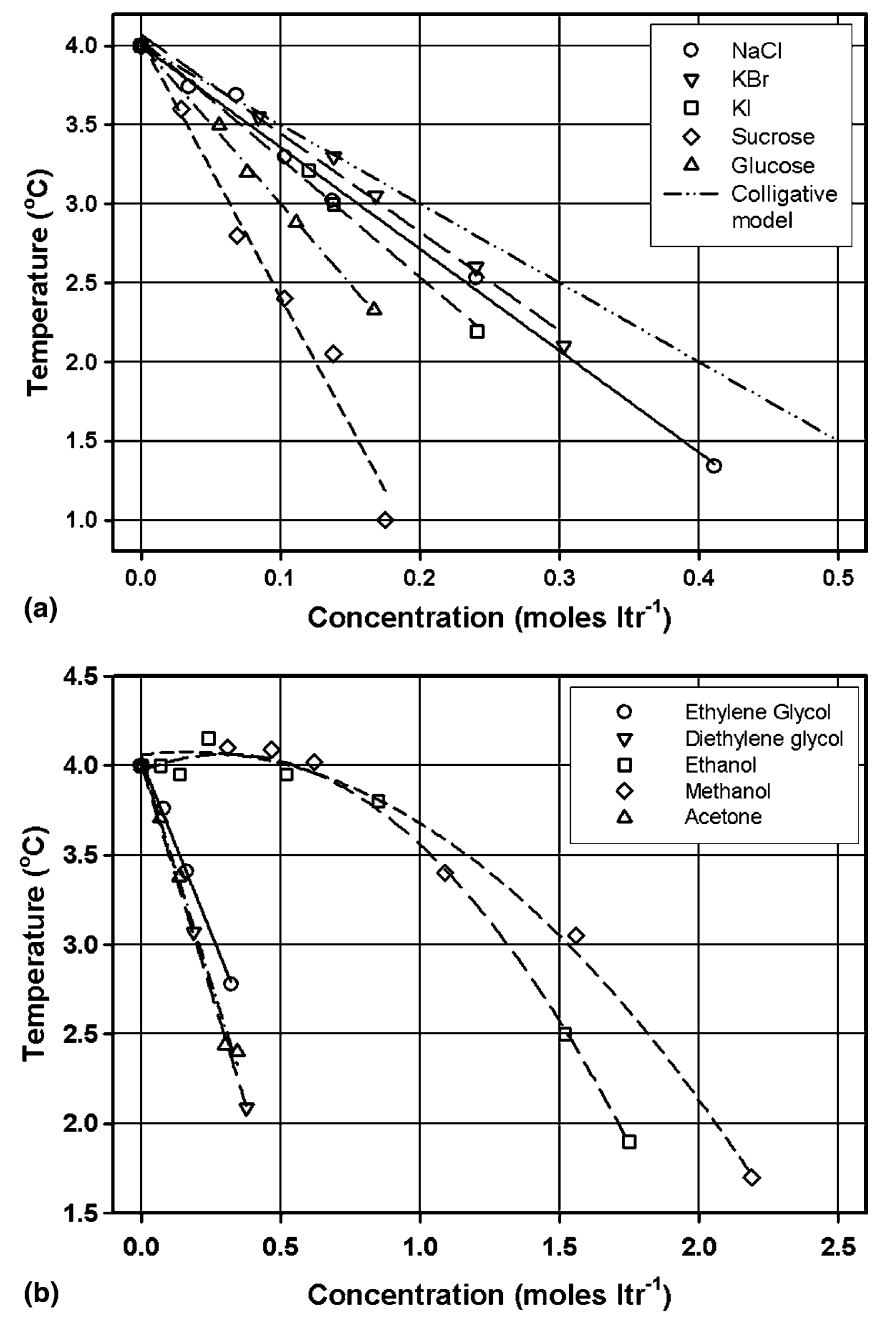

Fig. 11. As for Fig. 10, with behaviour of the temperature of maximum density as a function of molar concentration. The uppermost dashed line in (a) represents one possible colligative model, with a drop of $1{ }^{\circ} \mathrm{C}$ for an increase in concentration of $0.2 \mathrm{~mol}$ per litre.

of molar concentration. It is apparent from the latter that the shift of $T_{\rho \max }$ with increasing concentration is not a colligative property of the solutions (i.e. a property similar to the depression of the freezing temperature, or the elevation of the boiling temperature, both of which depend on the number of solute particles in solution rather than their nature). If the depression of $T_{\rho \max }$ was a colligative property, it would be expected that all of the experimental points would fall on the same line, such as the dashed line in Fig. 11 which shows a doubling of the $T_{\rho \max }$ depression as the molar concentration is doubled. Furthermore, the non-linear dependence of $T_{\rho \max }$ as a function of solute concentration for the monohydric alcohols (methanol, ethanol) clearly rules out a simple colligative dependence.

Results for three ionic solutes taken from [7] are shown in Fig. 12. These results were obtained using standard density measurement techniques (dilatometers). All of the ionic solutes reported in [7] show linear depressions of $T_{\rho \max }$ with increasing solute concentration. It is evident that there is good agreement in the case of $\mathrm{NaCl}$ between the results

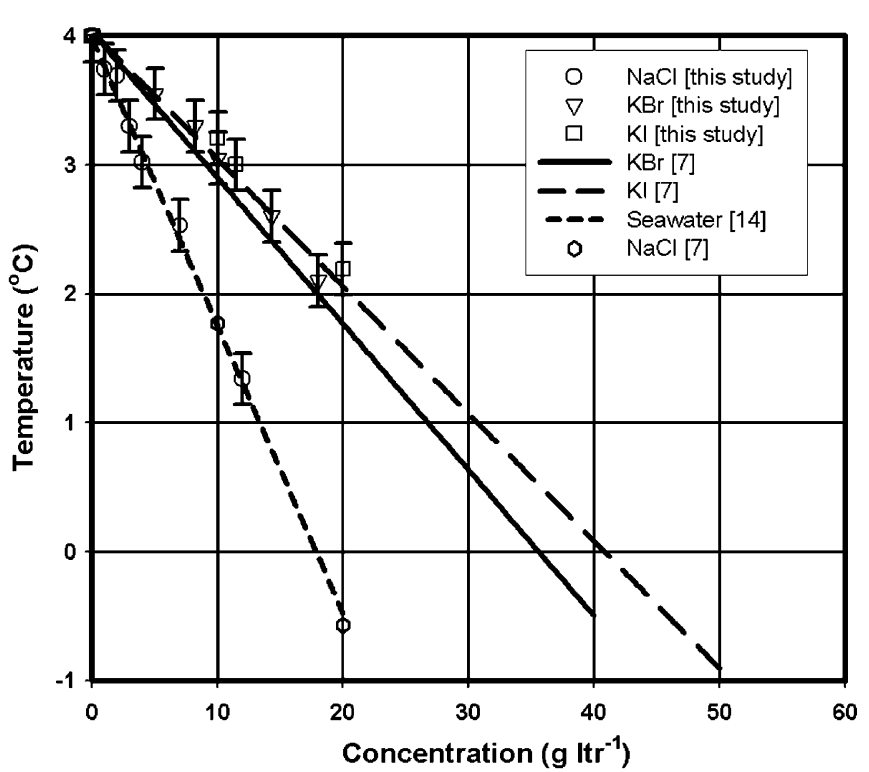

Fig. 12. A selection of results form this work compared with previous studies. Trend lines for $\mathrm{KBr}$ and $\mathrm{KI}$ are best fits to data taken form the International Critical Tables [7]. The hexagonal points without error bars for $\mathrm{NaCl}$ are also from [7]. The trend line for $\mathrm{NaCl}$ is derived from the seawater equation of state, taken from [14].

obtained in this work, the results of [7], and the seawater state equation quoted in [14]. For $\mathrm{KBr}$ and $\mathrm{KI}$ there are indications that the results obtained in this work fall somewhat higher than the best fit line to the results from [7], but such differences are not statistically significant (the slope for the $\mathrm{KBr}$ points from this work is $-0.0996 \pm 0.008 \mathrm{com}$ pared to a slope of $-0.110 \pm 0.002$ for the $\mathrm{KBr}$ points from [7]).

Sample sugar solutes (glucose, sucrose) were also tested for this work and it was found that these solutes also give rise to a linear depression of $T_{\rho \max }$; similar trends were found for a ketone (acetone) and both ethylene glycol and di-ethylene glycol (both dihydric alcohols, viz. possessing two hydroxyl groups). Departures from the linear depression of $T_{\rho \max }$ were found for the monohydric alcohols. In contrast to all other solutes tested, both methanol $\left(\mathrm{CH}_{3} \mathrm{OH}\right)$ and ethanol $\left(\mathrm{C}_{2} \mathrm{H}_{5} \mathrm{OH}\right)$ resulted in slight increases in $T_{\rho \max }$ at low concentrations, followed by a turnover and rapid decline of $T_{\rho \max }$ as the solute concentration increased. This non-linear behaviour, including the slight elevation of the $T_{\rho \max }$, was noted previously for ethanol [21].

When working with aqueous solutions there is the possibility of convective flows being induced by concentration gradients in addition to thermally induced convection. Convection driven by mass diffusion could under certain circumstances lead to a considerable increase in the complexity of the resulting flow patterns, and consequently to misinterpretation of the measurement of the temperature of the maximum density of the solution. The solutions tested in this work were dilute (typically $5 \%$ concentration or less) and well mixed. In addition, for substances such as 
sodium chloride and methanol in water, the chemical diffusivity is one hundred times smaller than the thermal diffusivity; for larger molecules such as sucrose, the ratio is even smaller $[22,23]$. The buoyancy effects due to any residual concentration gradients would be negligible in these circumstances in comparison to the substantial buoyancy imposed by the thermal gradient.

\section{Discussion and conclusions}

A technique has been devised to measure the temperature of maximum density of water solutions which is both accurate and simple to implement. Sources of uncertainty in the procedures described above can all be reduced if required. As with the zero-crossing approach advocated by Caldwell [14], the method described here does not rely on direct detection of an extremum in the density state function (in contrast to the more standard dilatometry techniques). The inherent accuracy of the approach arises from the detection of the sharp temperature transitions introduced by the migration of the boundary between the double convective cell from right to left of the sample chamber as the solution cools through the density anomaly.

It is evident both from historical measurements of $T_{\rho \max }$ and from the data presented here that the shift in the temperature of the maximum density as a function of solute nature and concentration does not follow any simple pattern. In particular, the non-linear dependence of $T_{\rho \max }$ as a function of concentration for the monohydric alcohols would seem to eliminate any simple dependence such as a colligative model whereby the shift of the temperature of maximum density would be independent of the nature of the species. This in turn draws a clear distinction between the behaviour of the temperature of maximum density and the depression of the temperature of freezing. To our knowledge there is as yet no model of the density maximum phenomenon of water which permits prediction of the temperature of density maximum given information on solute type and amount.

A study of how the temperature of the density maximum of water solutions varies as functions of both solute nature and concentration for fixed pressure conditions yields potentially useful insights into the molecular mechanism which gives rise to the density anomaly. It is speculated that the density maximum arises as a consequence of a balance between packing efficiency (high density mode) and bonding optimization (low density mode) (e.g. [4]). Whereas in most substances the packing density is optimized as the temperature is lowered (removal of vibrational kinetic energy permitting molecules to move closer together, thereby lowering the potential energy) it is postulated that in water it becomes energetically more favourable at lower temperatures for molecules to move further apart in order to optimize the energy of hydrogen bonding. Alterations in the angles of bonding and long-range Coulomb interactions may also contribute to the appearance of the density anomaly [2]. In such models, water at low temperatures is made up of a mixture of lower- and higher-density clustering, resulting in an extremum in the state function which for pure water at one atmosphere occurs at $3.98^{\circ} \mathrm{C}$. Adding a solute to the water presumably changes the balance of the lower- and higher-density modes. If the presence of the solute inhibits the formation of bond-optimized clustering, then the 'normal' packing optimization persists for longer as the sample is cooled, resulting in a depression of the temperature of the density maximum. It has been suggested [21] that the initial rise in the temperature of maximum density seen in the monohydric alcohols such as ethanol is related to the observed minimum in the partial molar volume at low alcohol concentrations (the partial molar volume is a measure of the apparent volume occupied by the solute when in solution). However, this minimum in partial molar volume corresponds to solute concentrations much larger than those which result in elevations of the temperature of maximum density; furthermore, the minimum in the partial molar volume is observed over wide ranges of temperature, and is not confined to temperatures in the vicinity of the density anomaly.

\section{Acknowledgements}

P.A.M. gratefully acknowledges support from the National University of Ireland, Maynooth, and the Irish Research Council for Science, Engineering and Technology.

\section{References}

[1] C.H. Cho, S. Singh, G.W. Robinson, An explanation of the density maximum in water, Phys. Rev. Lett. 76 (10) (1996) 1651-1654.

[2] C.H. Cho, S. Singh, G.W. Robinson, Understanding all of water's anomalies with a nonlocal potential, J. Chem. Phys. 107 (19) (1997) 7979-7988.

[3] H. Tanaka, Simple physical explanation of the unusual thermodynamic behaviour of liquid water, Phys. Rev. Lett. 80 (26) (1998) 57505753.

[4] P. Jedlovszky, M. Mezei, R. Vallauri, A molecular level explanation of the density maximum of liquid water from computer simulations with a polarizable potential model, Chem. Phys. Lett. 318 (2000) 155-160.

[5] Handbook of Chemistry and Physics, 65 ed., CRC Press, Boca Raton, FL, 1984.

[6] H.I.M. Veiga, L.P.N. Rebelo, M. Nunes de Ponte, J. Szydlowski, Water and Gallium at absolute negative pressures, Loci of maximum density and of melting, in: Fourteenth Symposium on Thermophysical Properties, June 25-30, 2000, Boulder, CO, USA.

[7] International Critical Tables of Numerical Data, Physics, Chemistry and Technology, vol. III, McGraw-Hill, New York, 1928.

[8] M. Despretz, Recherches sur le maximum de densite des dissolutions aqueuses, Ann. Chim. Phys. 70 (1839) 49-81.

[9] M. Despretz, Le maximum de densite des liquides, Ann. Chim. Phys. 73 (1840) 296-310.

[10] R. Wright, The effect of some simple electrolytes on the temperature of maximum density of water, J. Chem. Soc. 115 (1919) 119-126.

[11] M.F. Rossetti, Sur le maximum de densite et la dilatation de l'eau distillee, Ann. Chim. Phys. 10 (1867) 461-473.

[12] M.F. Rossetti, Sur le maximum de densite et la dilatation de l'eau distillee, de l'eau de l'Adriatique et de quelques solutions salines, Ann. Chim. Phys. 17 (1869) 370-384. 
[13] T.C. Hope, Experiments and observations upon the contraction of water by heat at low temperatures, Trans. Roy. Soc. Edinburgh 5 (1805) 379-405.

[14] D.R. Caldwell, The maximum density points of pure and saline water, Deep-Sea Res. 25 (1978) 175-181.

[15] M.F. Cawley, P. McBride, Flow visualization of free convective flow in a vertical cylinder of water in the vicinity of the density maximum, Int. J. Heat Mass Transfer 47 (2004) 1175-1186.

[16] N. Seki, S. Fukusako, H. Inaba, Free convective heat transfer with density inversion in a confined rectangular vessel, Warme- und Stoffubertragung 11 (1978) 145-156.

[17] D.S. Lin, M.W. Nansteel, Natural convection heat transfer in a square enclosure containing water near its density maximum, Int. J. Heat Mass Transfer 30 (11) (1987) 2319-2329.

[18] M.W. McDonough, A. Faghri, Experimental and numerical analyses of the natural convection of water through its density maximum in a rectangular enclosure, Int. J. Heat Mass Transfer 37 (5) (1994) $783-$ 801.

[19] C.D. Seybert, J.W. Evans, PIV measurements of velocity of water in the presence of ice and comparison with calculated values, Int. J. Heat Mass Transfer 48 (2005) 67-73.

[20] M. Griebel, T. Dornseifer, T. Neunhoeffer, Numerical Simulation in Fluid Dynamics - A Practical Introduction, Society for Industrial and Applied Mathematics (SIAM), Philadelphia, 1998.

[21] A.G. Mitchell, W.F.K. Wynne-Jones, Thermodynamic and other properties of solutions involving hydrogen bonding, Discuss. Faraday Soc. 15 (1953) 161-168.

[22] B. Gebhart, L. Pera, The nature of vertical natural convection flows resulting from the combined buoyancy effects of thermal and mass diffusion, Int. J. Heat Mass Transfer 14 (1971) 2025-2050.

[23] D.J. Tritton, Physical Fluid Dynamics, second ed., Oxford University Press, 1988. 